\title{
Ser historiador no século XXI ${ }^{1}$
}

\author{
To be Historian in the 21th Century
}

\section{Raquel Glezer*}

O sol se reparte em crimes

Espaçonaves, guerrilhas

Em cardinales bonitas

Em caras de presidentes

Em grandes beijos de amor

Em dentes, pernas, bandeiras

Bomba e Brigitte Bardot

$O$ sol nas bancas de revista Me enche de alegria e preguiça

Quem lê tanta notícia.... Caetano Veloso. Alegria, Alegria, 1967.

Criar meu web site Fazer minha home-page Com quantos gigabytes

Se faz uma jangada

Eu quero entrar na rede

Promover um debate

Juntar via Internet

Um grupo de tietes de Connecticut

Eu quero entrar na rede para contatar Os lares do Nepal, os bares do Gabão... Gilberto Gil. Pela Internet, 1997.

${ }^{1}$ Uma versão preliminar deste texto foi apresentada como conferência na Universidade Estadual de Londrina/UEL/PR em out. 2013.

*Profa. Titular - Departamento de História - Faculdade de Filosofia, Letras e Ciências Humanas -FFLCH, da Universidade de São Paulo - USP. Av. Prof. Lineu Prestes, 338, sala I-2, Cidade Universitária Armando de Salles Oliveira, Butantã, CEP 05500-910, São Paulo/SP/BR; e-mail: raglezer@usp.br. 


\section{RESUMO}

Este artigo apresenta as mudanças no processo de formação do historiador a partir das transformações decorrentes da passagem da galáxia de Gutenberg para a galáxia Marconi, relacionando-as com as características da sociedade de massa contemporânea, com acesso à informação em tempo real e com identidade fragmentada.

Palavras-chave: Galáxia de Gutenberg. Galáxia Marconi. Formação do historiador. Sociedade de massa. Tempo real. Identidade fragmentada.

\section{ABSTRACT}

This paper presents the changes in the construction process of a historian considering the transformations from the transition of the Gutenberg galaxy to the Marconi galaxy and relating them to the characteristics of a contemporary mass society, which has access to information in real time and a divided identity.

Keywords: Gutenberg galaxy. Marconi galaxy. Historian Formation. Mass society. Real time. Divided identity.

$\mathrm{Na}$ epigrafe as duas letras de músicas citadas indicam a alteração fundamental do final do século XX em termos de acesso à informação - a passagem da galáxia de Gutenberg para a galáxia Marconi (CASTELLS, 1999, 2003; MCLUHAN, 1972).

A proposta de uma reflexão sobre a atividade profissional de historiador, estruturada no século XIX como artesanal, individual e solitária, deve levar em consideração tal transformação, pois ela integra os desafios profissionais a serem enfrentados no século XXI.

Estamos na segunda década do século XXI e como o mundo não acabou no ano 2000 (deixando todos os milenaristas decepcionados, pois agora terão que aguardar o final deste século, o que apesar do aumento da longevidade humana parece ser ainda um pouco problemático); o 'bug' do milênio não aconteceu (deletando arquivos de todos computadores do planeta ${ }^{2}$ e instalando o caos planetário) e a história não chegou ao fim (como havia previsto um 'otimista' quase incurável que depois voltou atrás) (FUKUYAMA, 1992, 2013).

\footnotetext{
${ }^{2}$ Para os que nasceram na última década do século XX e no XXI: Os computadores mais antigos tinham memória limitada e os programas procuravam simplificar as informações coletadas para diminuir o espaço de armazenamento dos dados. Alguns especialistas previram que a passagem do milênio em 2000 provocaria grandes transtornos em todos os sistemas informatizados, que poderiam retornar para 1900, o que acabou não acontecendo, pois a tecnologia foi alterada de forma a atender todos os computadores e programas. (WIKIPEDIA, 2000).
} 
Ao contrário, as sociedades parecem estar enfrentando um processo cada vez mais acelerado de mudanças, no qual eventos, conhecimentos e tecnologias crescem e se expandem pelo planeta geometricamente. O chamado Tempo Real, em que todos os sistemas de informação e sistemas econômicos estão conectados e possíveis de serem acessados, desde que pelo menos parcela de uma dada sociedade se inclua em determinadas tecnologias, tornou-se uma realidade.

E a sensação de que não conseguimos acompanhar o que está acontecendo é angustiante. Estamos todos defasados em termos de acontecimentos que estão ocorrendo no país e no mundo, para não falar nos eventos artísticos, científicos e culturais e no domínio sobre as tecnologias, que estão em constante inovação (qual o aplicativo que você baixou hoje?).

A miríade de dados emitidos e recebidos acaba transformando todas as informações em lampejos, sem possibilidade de acompanhamento ou de crítica no momento da recepção.

E o que tais situações contemporâneas tem a ver com a História? Parece que foi há pouco tempo, pouco mais de século e meio - intervalo pequeno em termos históricos, já que a História começara a existir na civilização grega, embora como um gênero sublunar (VEYNE, 1971) - que ela separou-se das Letras, da Filosofia e da Teologia, após quase dois séculos de divergências metodológicas que foram se estruturando e solidificando, definindo-se como um campo de conhecimento específico, com método e procedimentos próprios, o que lhe permitiu apresentar-se como uma ciência humana: a ciência do homem no tempo, em todos os aspectos possíveis.

O processo de formação de historiador realizado em instituição universitária, mas separado do filósofo, do teólogo estrito senso e do romancista, estruturado em meados do século XIX nas universidades de língua alemã e espalhado pelo mundo ocidental por seus discípulos, preocupado com a descrição do passado tal como aconteceu tornou-se dominante, deixando na sombra formas de construção e narrativas históricas que haviam se formulado através dos séculos em diversas sociedades e culturas, desqualificando-as e destinando-as ao limbo historiográfico (BREISACH, 2007).

Desde o aparecimento da proposta do método histórico surgiram críticas e questionamentos que apontavam as limitações de tal forma de trabalho, a partir mesmo dos centros de língua alemã e que também se espalharam por outras instituições universitárias.

No final do século XIX e no século XX as críticas se acentuaram em diversos países e outras propostas de atuação no método histórico e nas formulações teórico-metodológicas foram apresentadas e concretizadas. Acompanharam o desenvolvimento da civilização ocidental pós Revolução Industrial com vitalidade e podemos dizer que o limbo foi remexido e que as formas de construção das narrativas historiográficas que estavam 
obscurecidas reapareceram, somando-se a diversas outras, novas, decorrentes das mudanças socioeconômicas, culturais e tecnológicas.

A multiplicidade de fontes e de narrativas historiográficas criou problemas para a formação do historiador. Como manter a estruturação da formação e da profissão diante das mudanças?

Inicialmente, a tendência geral foi de manter a formação básica, clássica (domínio das fontes e da bibliografia - erudição, das técnicas de leitura e de análise de texto - exegese e do exercício de compreensão e interpretação - síntese) e ir acrescentando as novas propostas de fontes com as análises pertinentes - o que levou a camadas e camadas de informação/formação se superpondo. A formação do historiador deveria manter os padrões acadêmicos definidos pelo campo, com todas as condicionantes que Michel de Certeau, no último quartel do século XX, destaca (CERTEAU, 1975).

E na prática cotidiana, em razão das múltiplas possibilidades de fontes, de análises e de narrativas, o processo de formação foi se tornando tão complexo que a especialização se tornou obrigatória desde o início do curso de graduação. Em nossos dias, ficou impossível a um ser humano cobrir todas as fontes possíveis existentes e as formas de analisa-las, pois os objetos de pesquisa se tornaram variados e diversificados.

E no currículo universitário, com tempo limitado de duração, não cabem todas as maneiras de exploração de fontes, todas as análises possíveis, todas as formulações teóricometodológicas, todas as formas de narrativas historiográficas, e mais as leituras obrigatórias das áreas correlatas, que estão em processo de ampliação constante.

O processo de formação, em nossos dias, é uma delimitação precoce de áreas de interesses, de especialidade, com as disciplinas das zonas de confluência, cada qual com seu vocabulário, enfoques, permutas de perspectivas, etc.

E em função da variedade e complexidade do campo historiográfico e das rápidas mudanças em suportes tecnológicos, como ser historiador no século XXI? O que é história? E o que não é história? Todo passado é história? E os acontecimentos do tempo presente, como devem ser tratados? E qual a sua duração? (GLEZER, 2007).

Há diferenças em ser historiador em nossos dias em relação ao historiador dos séculos XIX e XX?

No senso comum da sociedade ocidental contemporânea, o objeto dos historiadores é o passado e ele é homogêneo e verdadeiro. A história é o passado, como conhecido e reconhecido pelo senso comum proporcionado pelo sistema educacional quase que universal - uma história política de amigos e inimigos; grandes homens, heróis e vilões; grandes eventos como guerras e revoluções. 
Para os historiadores diletantes, autores de divulgação histórica, romancistas, qualquer evento considerado significativo é passado e pode ser reproduzido tal como aconteceu, baseado em fontes conhecidas e na bibliografia sobre o assunto existente.

Para nós, historiadores acadêmicos, de formação especializada, o passado é uma construção das narrativas possíveis - uma História. Continua a ser baseada em fontes variadas e diversas, que são submetidas a análises minuciosas para verificação de sua elaboração, das informações, desmontadas em seus inúmeros detalhes, lidas e relidas, buscando o não-dito e o implícito, descritas, explicadas, confrontadas com outras fontes e com a bibliografia sobre o mesmo tema e período para os exercícios de compreensão, interpretação e síntese.

Mas sabemos que um trajeto de pesquisa não encerra todas as possibilidades de análise e compreensão, não visa reconstruir o passado ou atingir a verdade do que aconteceu, pois o trabalho acadêmico possui limitações pelo enfoque, perspectiva analítica, conhecimento disponível e data de produção - o conhecimento é um processo contínuo e sua descrição tende a ser relativa ao momento da produção.

Para nós, historiadores com formação universitária, a narrativa histórica, que é o trabalho historiográfico, está sempre em transformação, pois é contemporâneo, marcado pelas questões candentes do momento em que o historiador vive (CROCE, 1955).

A sociedade atual, em um grande grupo de países, entre os quais o nosso, é uma sociedade de massas, fenômeno decorrente das transformações provocadas pelas industrializações dos séculos XIX e XX: urbanização acelerada, alfabetização quase que universal, mudanças demográficas cada vez mais rápidas, meios de transporte quase que universalizados e rápidos e meios de comunicação disseminados entre a população. As clivagens internas em cada país são gritantes: a desigualdade econômica e social acompanha o processo de modernização econômica acelerada, mantendo uma parcela da população fora das vantagens e das chamadas benesses da sociedade de massas, pois as diferenças econômicas e as crises são inerentes ao sistema capitalista de produção.

A sociedade de massas urbanizada é individualista ao extremo, embora haja multidões à procura de elementos materiais que proporcionem satisfação imediata de seus desejos. E é consumista pela situação isolada de cada indivíduo membro de sociedade de massas com identidade fragmentada, composta por milhares de pessoas que sempre precisam de algo a mais para sua auto identificação e satisfação momentânea. A individualização exacerbada pode levar ao isolacionismo e a negação do outro, mas também pode permitir o reconhecimento das diferenças e a aceitação do outro (MOSCOVICI, 2003).

Podemos lamentar pelo mundo que quase desapareceu: agrário sem industrialização; núcleos comunitários de produção e consumo; alta coesão e forte coerção social entre os 
membros do grupo; isolamento; preconceitos contra os diferentes e exóticos - todos os outros. É pouco provável que desejássemos retornar ao mundo agrário com suas características. Contudo, as permanências de experiências milenares de vida continuam a fazer efeito. Se de um lado há uma retomada e valoração da natureza e da vida rural, por outro há a exacerbação do isolacionismo. E em decorrência delas, estamos vendo o aflorar das intolerâncias e das rejeições.

Para nós, historiadores, estudiosos, pesquisadores em cada um dos múltiplos campos dos estudos históricos a História na sociedade contemporânea aparece de forma clara e evidente: a sociedade em que estamos inseridos é uma sociedade histórica em todos os sentidos, que não pode dispensar a sua historicidade, pois se formula em torno de uma relativamente longa herança cultural, que por pressuposto articula todos os aspectos da vida social.

Somos todos integrantes da sociedade ocidental cristã, europeia inicialmente, que se espalhou pelos outros continentes e que após o processo de laicização passou a ser a sociedade ocidental contemporânea. E possuímos a clara noção de nossa relação com o passado, que vai desde a forma de contagem do tempo, à seleção de um passado que criou referenciais culturais comuns, elementos da cultura erudita e popular, que quando apresentados permitem reconhecimento e relações sociais entre formações sociais mesmo que cronológica e geograficamente distantes.

A forma de contagem do tempo a partir da figura do Cristo como marco singular e divisor de um tempo infinito que se estrutura em passado, presente e futuro, inicialmente cristã e ocidental, se tornou predominante, de forma que mesmo para culturas e civilizações diferentes acaba servindo como elemento indicativo.

A concepção de tempo tripartite, linear, progressivo, finalista que teve como forma inicial a concepção apocalíptica de final dos tempos - característica da Teologia Cristã e da Filosofia Cristã de História, foi sendo laicizada até as concepções finalistas como Estado, Progresso, Revolução (GLEZER, 2002).

Talvez um dos problemas da sociedade contemporânea ocidental seja o de não possuir mais uma finalidade direcionada para o futuro, pela rapidez das transformações tecnológicas do final do século XX e início deste que permitem a comunicação instantânea entre os seres humanos e a sensação que o presente está em constante alteração. A recepção de fatos variados e diversos imediatamente ao acontecido - vantagem das comunicações em tempo real acaba trazendo a presentificação de todas as informações e de todos os momentos. A avalanche de informações aparentemente destrói a reflexão sobre os fatos e a necessidade de referenciar os fatos ao seu contexto, isto é, à sua história. 
E é em tal situação que o historiador do século XXI vai atuar. Se na vivência cotidiana das pessoas conectadas em tempo real ao universo das informações a história enquanto conhecimento não parece ser necessária, pois exige algum tempo para configuração de sentido e, portanto, para a compreensão do que está ocorrendo, por outro lado, a multiplicidade de usos do passado e do conhecimento histórico que permeia a vida cotidiana, nos impressiona por sua variedade e diversidade, que são de tal monta que nem nos damos conta disso, já que estamos imersos nela.

Variedade de fontes e documentos em suportes tão diferenciados que os cursos de formação de profissionais em história não conseguem colocar no horizonte de aprendizagem.

Em nosso entender, enquanto professores de cursos de história formamos profissionais: professores de história para os diversos níveis de ensino e pesquisadores.

Pensamos a história como processo de conhecimento social e também como um específico produto cultural - realizado por pesquisadores, professores e historiadores - com um produto historiográfico (monografia, capitulo de livro, artigo em revista acadêmica, artigo de divulgação científica). Mas também integram o fazer historiográfico em diversos níveis de profundidade outras instancias culturais: escolas, através do conhecimento escolar; os museus, arquivos e bibliotecas com seus acervos materiais e atividades de curadoria para preservação e divulgação. Para não falarmos dos acervos imateriais, parte da cultura não letrada, que integram a cultura popular no cotidiano dos cidadãos, e que hoje são tão valorizados.

Do produto acadêmico surgem muitos outros produtos, em diversas formas de tratamento, que vão do material didático em amplo espectro, revistas especializadas em divulgação histórica, documentários, filmes, história em quadrinhos, etc., incluindo aí a formação de outros profissionais como os docentes em diversos níveis de ensino e profissionais em diversos campos. Alunos em formação escolar também produzem um tipo de conhecimento histórico - o saber histórico escolar. Mesmo se deixarmos de lado os produtos acima citados, há uma miríade de produtos que recorrem ao conhecimento histórico como fundamentação, como os jogos em vídeo interativos e especialmente os jogos de 'rpg' - interpretação de personagens.

$\mathrm{Na}$ sociedade de massas, de modo aparentemente contraditório, há uma grande exploração do conhecimento histórico, quer como passado, como memória, como curiosidade - lugares de memória, monumentos e museus se tornaram alvos de dois fenômenos relevantes: inicialmente, o da valorização do espaço construído para exaltação de um elemento do passado como lazer 'respeitável' - o que os transformou em objetos de desejo e referência não apenas para a visitação escolar mas para toda sociedade. Eles foram transformados em itens obrigatórios no lazer direcionado e controlado das atividades de 
férias e viagens de negócios. Depois, foram transformados em objetos de espetacularização, quando exposições e exibições acabam sendo megaeventos, com milhares de visitantes percorrendo o espaço delimitado - resultado da utilização tanto de elementos tecnológicos como dos meios de comunicação para divulgação do evento (CHESNEAUX, 1983).

Nos produtos culturais acima citados, o conhecimento histórico e a historiografia - os argumentos sobre o passado e as interpretações sobre ele - permeiam a seleção, a construção e a divulgação.

Retomando a questão de como ser historiador no século XXI, devemos destacar que há algumas vantagens em estar distante geograficamente dos centros produtores do conhecimento histórico, entre elas a de poder utilizar as mais variadas formas de produção historiográfica, sem a reprodução dos conflitos existentes entre todas as possibilidades de atuação profissional do historiador. Não precisamos ficar justificando a cada momento o tipo de conhecimento histórico que estamos produzindo - mais ou menos cientifico em relação ao padrão oitocentista do que era História (PERL; DAVIS; ALLEN, 2011).

Por outro lado, a distância não é mais impedimento total para o desenvolvimento de uma pesquisa, pois há vantagens decorrentes da existência de condições de acesso a bibliotecas e arquivos a distância, pelo processo de informatização e de divulgação de livros e documentos, o que ocorre tanto a nível internacional como nacional.

No momento da sociedade em que vivemos, imersa na tecnologia de informação e nos acontecimentos em tempo real, alunos de cursos de história e mesmo historiadores acadêmicos podem se sentir como 'aves estranhas' diante dos outros: o seu processo de formação e de trabalho parece estar na contramão do cotidiano, com exigências de leitura (método de leitura, análise, interpretação e síntese), reflexão crítica sobre a bibliografia já produzida e documentos em suportes diversos (do pergaminho ao papel, das imagens inscritas em pedra as tridimensionais em vários suportes, dos dados censitários aos econômicos em bases distintas e mutáveis, produtos culturais desde os de uso mais cotidiano aos mais sofisticados). Ao contrário do mundo em tempo real - imediato, instantâneo, fragmentado e sem continuidade, parece que o tempo do historiador é mais lento, descolado das transformações, quase imutável, como se a história fosse sempre igual, com um passado pronto, homogêneo e uniforme.

Quando observamos o campo dos estudos históricos quer no país quer nos centros internacionais de referência, verificamos que houve uma certa rapidez nas mutações do trabalho do historiador, que ocorreu nas formas de pesquisa, nos referenciais teóricos necessários para a descrição e análise dos fenômenos em questão, nas formas narrativas dos textos. Novos campos estão sempre sendo desenvolvidos, demarcando as áreas de interesse da sociedade sobre si mesma. E como há mudanças, há disputas sobre relevância, financiamento, espaço acadêmico, etc. 
Cabe aos historiadores do século XXI encontrar as formas de atuação nos diversos espaços sociais e culturais em que estão e estarão imersos. Deverão eles desenvolver novas maneiras de lidar com a documentação evanescente como as das redes sociais, com os factoides e com as novas formas de controle que os governos tendem a colocar como limite as liberdades individuais.

Das capacidades de percepção dos fenômenos emergentes da sociedade e do domínio da tecnologia de informação dependerá a continuidade dos estudos históricos e dos historiadores.

\section{Bibliografia}

BREISACH, Ernest. Historiography; ancient, medieval \& modern. $3^{\text {rd. }}$ ed. Chicago: The University of Chicago Press, 2007.

CASTELLS, Manuel. A galáxia da internet: reflexões sobre a internet, os negócios e a sociedade. Rio de Janeiro: Jorge Zahar, 2003.

_. A sociedade em rede. São Paulo: Paz e Terra,1999.

CERTEAU, Michel de. A operação historiográfica. In: . A escrita da história. Rio de Janeiro: Forense- Universitária, 1975. p. 65-122.

CHESNEAUX, Jean. De la modernité. Paris: La Découverte, 1983.

CROCE, Benedetto. Teoria y historia de la historiografia. Buenos Aires: EUDEBA, 1955.

FUKUYAMA, Francis. As origens da ordem política: dos tempos pré-humanos até à Revolução Francesa. Rio de Janeiro: Rocco, 2013.

FUKUYAMA, Francis. O fim da história e o último homem. Rio de Janeiro: Rocco, 1992.

GIL, Gilberto. Pela internet.1997. Disponível em: <http://letras.mus.br/gilberto-gil/68924//>. Acesso em: 15 out. 2014.

GLEZER, Raquel. A história e o tempo presente. In: BRUNI, José Carlos; MENNA-BARRETO, Luiz; MARQUES, Nelson (Org.). Decifrando o tempo presente. São Paulo: UNESP, 2007. p. 23-44.

GLEZER, Raquel. Tempo e história. Ciência e Cultura, São Paulo, v. 54, n. 2, p. 23-24, 2002.

MCLUHAN, Marshall. A galáxia de Gutenberg: a formação do homem tipográfico. São Paulo: Nacional, 1972. 


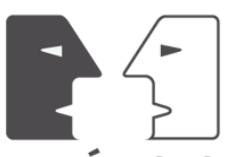

ANTÍTESES

MOSCOVICI, Serge. Representações sociais: investigações em psicologia social. Petrópolis: Vozes. 2003.

PERL, Jeffrey M.; DAVIS, Natalie Z.; ALLEN, Barry. Fuzzy studies: A symposium on the consequence of blur. Common Knowledge, Durham, v. 17, n. 3, p. 441-449, 2011.

VELOSO, Caetano. Alegria, alegria. 1967. Disponível em: $<$ http://letras.mus.br/caetanoveloso/43867/>. Acesso em: 10 set. 2014.

VEYNE, Paul. Comment on écrit l'histoire. Paris: Seuil, 1971.

WIKIPÉDIA. Problema do ano 2000. Disponível em:

<pt.wikipedia.org/wiki/Problema_do_ano_2000>. Acesso em 22 set. 2014 